\title{
The Impact of Hostel Life on Personality Attributes of Young Adults: Case Study of a Public Sector University
}

\author{
Samina Rafique ${ }^{1 *}$ and Waseem $\mathbf{M}^{2}$ \\ ${ }^{1}$ Chief Medical Officer, Pakistan \\ ${ }^{2}$ Nishtar Medical University, Pakistan
}

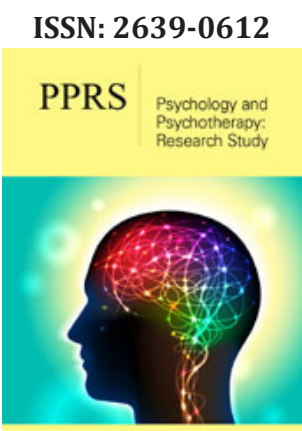

*Corresponding author: Samina Rafique, Chief Medical Officer, Pakistan

\section{Submission: 制 March 17, 2021}

Published: 温 March 23, 2021

\section{Volume 4 - Issue 4}

How to cite this article: Samina Rafique1, Waseem M. The Impact of Hostel Life on Personality Attributes of Young Adults: Case Study of a Public Sector University. Psychol Psychother Res Stud. 4(4). PPRS. 0005952021. DOI: 10.31031/PPRS.2021.04.000595

Copyright@ Samina Rafique, This article is distributed under the terms of the Creative Commons Attribution 4.0 International License, which permits unrestricted use and redistribution provided that the original author and source are credited.

\begin{abstract}
Background: During transitional period from adolescent to adulthood significant changes occur in the personality and behavior of the individual which are determined mainly by genetics but transaction with social environment also plays a role. Hence adolescents living away from family in hostels of higher educational institutes may get influenced by the environment there in. This study investigated the perception of female students about the environment of hostels and its impact on personality development.
\end{abstract}

Methods: A cross sectional survey was carried out in a public sector university through a questionnaire. The responses about the various effects of hostel life were measured on a 5-point likert scale. Two groups of the study participants were then created according to age and results were dichotomized for statistical analysis. Chi-square test was applied for comparison among the two study groups.

Results: The results showed that from amongst the various factors enlisted in the questionnaire, management skills were most agreed characteristic (92\%) achieved by residing in hostel. Similarly, expense management, emotional stability and public dealing were agreed upon by $86 \%, 85 \%$ and $86 \%$ respectively. While 199 out of 272 respondents confessed to gain confidence and 230 hostel residents realized that they became more groomed. The results were significant at $p<.0001$ for all study variables between two groups of respondents. A few undesirable aspects of hostel life were also identified yet a great majority of the girls were not hesitant in recommending hostel residence to other scholars.

Conclusion: Hostel residence besides providing opportunity for higher education to the students of distant towns can modify the behavior and personality of the residents in a positive manner.

Keywords: Hostel life; Behavior modification; Personality development

\section{Introduction}

Student's life in universities is a transitional period from adolescence to adulthood after which individuals normally settle into their adult roles. It is a turbulent stage of evolution which involves noteworthy changes in the personality and behavior of the students. Personality attributes/traits may be described as temperament and propensity to think, feel and act. Studies suggest that genetics and environmental influences work together to endorse personality development during transition to adulthood [1,2]. Family environment has a significant effect on the personality traits leading to modifications in behavior and adjustments through the course of life [3]. However, for the pursuit of higher education many people have to depart from their homes and have to stay away in hostels where environment is entirely different to that in the home. In Pakistan the word "Hostel" refers to student accommodations, which are usually provided by the educational institutions under the supervision of university/college staff. It has been observed that distinct atmosphere of hostels can influence individual's behavior and life style pattern [4].

Hostels can be described as "a practical human laboratory "that shapes, sharpens and refines the individual's personality and conduct [4]. The environment of hostels can be more favorable for study and is self-governing [5]. Hostels allow social interaction because residents have to share rooms and communal areas such as lounges, kitchen, dining hall and internet café etc. Thus, residents learn new experiences of life with their fellow mates and get trained for teamwork, through helping, caring, sharing, and developing sense of responsibility. All these factors can influence the shaping of personality [6]. Moreover, the residents have to abide by certain rules which make them more disciplined and punctual. According to a 
study [7] hostel residents are more determined, self-sufficient, and confident and possess more optimistic attitude than non-resident students.

Like many countries of the world, in Pakistan, higher education institutions are set up in the suburbs of big cities. A large majority of the aspiring students belong to distant smaller towns thus have to reside in hostels. Consequently, given the young age at which this happens, the educational facility and hostel environment plays a pivotal role in the development of their personalities. However, the studies pertaining to the role of hostel residence on personality attributes of individuals are very limited in Pakistan and most of these only appraise the academic advantages of the boarding system over the day scholar system $[8,9]$ Therefore the present study was planned which aimed to explore the perception of female university students about the impact of hostel life on their psychological and behavioral development. The results of the study may help parents and teachers to understand the phenomenon of adjustment through social exposure during this important transitional period of a student's life and the significance of living on campus in shaping personality of individuals. The study was approved by research committee, Bahauddin Zakariya University, Multan.

\section{Material and Methods}

This study was conducted in Bahauddin Zakariya Uinversity, Multan during March 2019. There are 7 girls hostel situated on the campus premises with more than 600 students in each hall of residence. Depending upon the degree program, a student has to live for 2-4 years or more (in case of a doctoral degree) in the hostel. Sample size was calculated to be 341 and participants were recruited by convenient sampling method. In order to get a clear verdict, students having a stay of one year or more were included. A pilot study was conducted by interviewing 20 senior students, who have had stayed in hostels for their education. A questionnaire was then prepared comprising of four parts. The first part of the survey consisted of demographic characteristics of the participants and the second part comprised certain features of an individual's personality that can be modified or influenced by residing in hostel, third part inquired about perception of any undesirable effects of hostel life. The final part was about recommending hostel living to other students.

Following components were included:

1. Social interaction and enjoyment

2. Confidence building

3. Management

4. Expense management

5. Emotional stability

6. Public dealing

7. Self grooming

8. Better understanding of curriculum

9. Do you perceive any undesirable consequences of living in hostel
10. Falling in bad company

11. Careless attitude about the studies

12. Home sickness

13. Others

Do you recommend hostel residence for other students?

1. Yes

2. No

The response was calculated on a 5-point Likert scale. For analytical purposes the participants of the study were divided into two groups based on age. The first group consisted of girls of the age above 21 years and the second batch was 19-21 years old while average stay of the two groups in hostel was 3.5 years and 1.5 year respectively. The responses were then dichotomized for agreed (strongly agreed, agreed) and disagreed (strongly disagreed, disagreed, neutral). Chi-square test was applied to examine the relation between age and perception of influence of hostel life on different aspects of personality. Pearson's correlation coefficient was calculated to observe the association between various variables examined.

Result

Table 1: Demographic characteristic of study participants.

\begin{tabular}{|c|c|}
\hline Characteristics & Number (\%) \\
\hline Age (years) & $22.4 \pm 1.8$ \\
\hline Duration of hostel stay (years) & $3 \pm 1.4$ \\
\hline Economic background (Family Income) & \\
\hline Lower middle* & $80(29.4)$ \\
\hline Middle & $161(59.5)$ \\
\hline Upper middleı̌ & $31(11.3)$ \\
\hline Family Background & $180(66)$ \\
\hline Urban & $92(33.8)$ \\
\hline Rural & \\
\hline
\end{tabular}

(* monthly income of family up to Rs 50,000/month, q monthly income Rs.50,000-100,000/month $\breve{1}$ : monthly income $>100,000 /$ month).

Out of 341 questionnaires 272 were completed and returned. Response rate remained $79.7 \%$. The demographic characteristics of study participants are described in Table 1 which shows that average age of the participants was $22.4 \pm 1.8$ years. Average duration of stay in hostel remained $3 \pm 1.4$ years. The table depicts that majority of the girls (59.9\%) belonged to middle economic class while $29.4 \%$ to lower middle and $11.3 \%$ hostel residents came from the upper economic class. Results regarding effects of hostel environment on the personality of the residents are displayed in Figure 1 which demonstrated that the most important aspect of hostel life remained management learning which was agreed by $92 \%$ (251) of the hostellers. Many $(199,75 \%)$ study contributors felt that their confidence boosted during hostel stay, 241 girls out of $272(89 \%)$ perceived that hostel life is a source of social interaction 
and enjoyment, expense management was learnt by $86 \%(n=234)$, emotional stability by 220 (85\%, p <.05), public dealing by 86 $\%$ and self grooming by $80 \%$ of the study participants. 223 (81.9 $\%$ ) of the study contributors declared hostel as to have a superior study atmosphere. A chi-square test of goodness was performed to elucidate the discrepancies between two groups of the participants. The results were significant at $\mathrm{p}<.0001$ for all of the variables (Table 2).

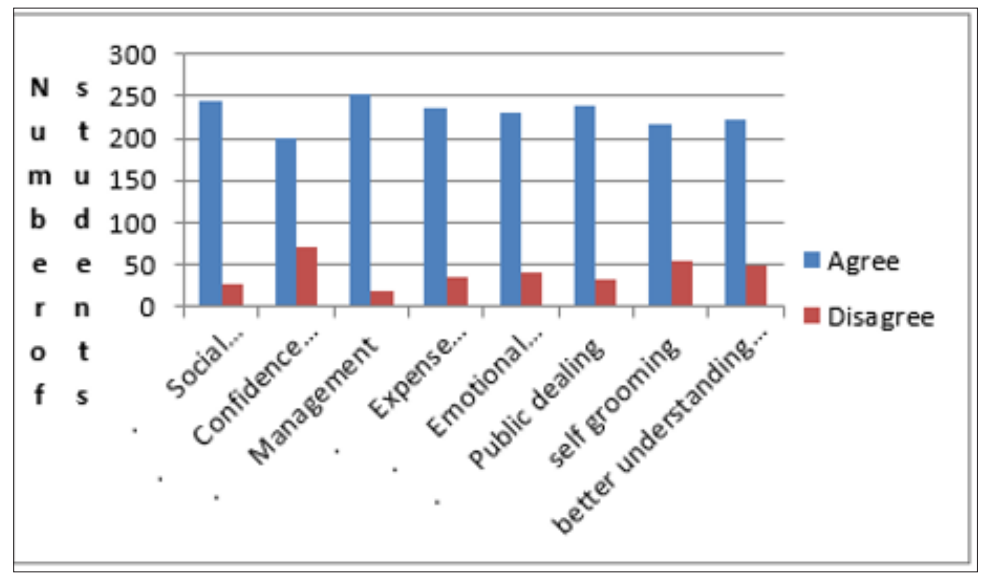

Figure 1: Perception of student about various components of behavior affected/improved by hostel residence.

Table 2: Statiscal analysis of different elements of personality influenced by hostel residence.

\begin{tabular}{|c|c|c|c|c|c|c|}
\hline & \multirow{4}{*}{ Statements } & Respons & & & & \multirow{4}{*}{$P$ value } \\
\hline & & \multicolumn{4}{|c|}{ Age } & \\
\hline & & \multicolumn{2}{|c|}{$>21$} & \multicolumn{2}{|c|}{$19-21$} & \\
\hline & & Agree & disagree & agree & disagree & \\
\hline 1 & Social interaction & 168 & 3 & 73 & 28 & $<.0001$ \\
\hline 2 & Confidence building & 169 & 2 & 30 & 71 & $<.0001$ \\
\hline 3 & Management & 167 & 4 & 84 & 17 & $<.0001$ \\
\hline 4 & Expense management & 168 & 3 & 66 & 35 & $<.0001$ \\
\hline 5 & Emotional stability & 150 & 21 & 70 & 31 & $<.0001$ \\
\hline 6 & Public dealing & 167 & 4 & 60 & 41 & $<.000 ` 1$ \\
\hline 7 & Selfgrooming & 169 & 2 & 61 & 40 & $<.0001$ \\
\hline 8 & Better understanding of curriculum & 152 & 19 & 61 & 40 & \\
\hline
\end{tabular}

The relationship among different study components was also observed and Pearson's correlation co efficient was determined. All possible effects numerated in the second part of the questionnaire exhibited strong positive association (Table3). The results about the unwanted aspects of hostel life are illustrated in Figure 2. The figure demonstrated the most mentioned negative or unwanted aspect of hostel life remained homesickness which was identified by 241 residents. 138 out of 272 girls perceived that some of the students in hostel may show careless attitude about their studies and spend their time in useless activities while 77 girls pointed out the likelihood of falling into bad company. When asked about recommending the hostel residence for the sake of higher studies, a great majority (241 out of 272) of the students recommend hostel residence for other scholars.

Table 3: Pearson's correlation of different study variables numbered according to the sequence listed in the questionnaire.

\begin{tabular}{|c|c|c|c|c|c|c|c|}
\hline $\mathbf{1}$ & $\mathbf{1}$ & $\mathbf{2}$ & $\mathbf{3}$ & $\mathbf{4}$ & $\mathbf{5}$ & $\mathbf{6}$ & $\mathbf{7}$ \\
\hline 2 & & $0.455^{* * *}$ & $0.67733^{* * *}$ & $0.612^{* * *}$ & $0.49197^{* * *}$ & $0.63127^{* * *}$ & $0.359^{* * *}$ \\
\hline 3 & & & $0.7996^{* * *}$ & $0.6387^{* * *}$ & $0.78^{* * *}$ & $0.7075^{* * *}$ & $0.3356^{* * *}$ \\
\hline 4 & & & & $0.8224^{* * *}$ & $0.7633^{* * *}$ & $0.8224^{* * *}$ & $0.6152^{* * *}$ \\
\hline 5 & & & & & $0.7886^{* * *}$ & $0.8522^{* * *}$ & $0.8534^{* * *}$ \\
\hline 6 & & & & & & $0.8958^{* * *}$ & $0.4981^{* * *}$ \\
\hline 7 & & & & & & & $0.5691^{* * *}$ \\
\hline 8 & & & & & & & \\
\hline
\end{tabular}




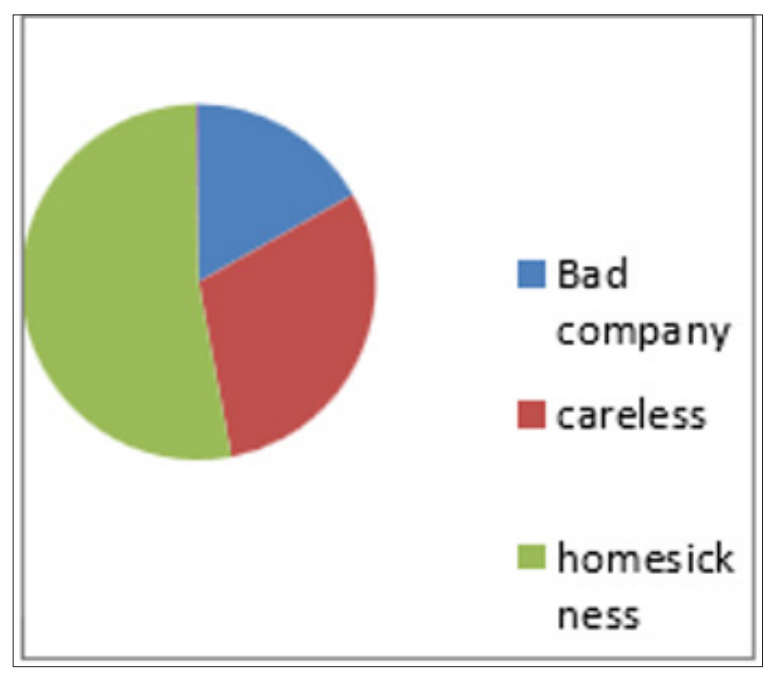

Figure 2: Undesirable consequence of hostel life, perceived by the residents.

\section{Discussion}

The study explores the influence of hostel life on the psychology and conduct of the residents. Most (92\%) of the students in our study affirmed that they attained better management skills while residing in the hostel. In hostels every student is allotted a bed and a small cupboard so they get trained for space economy. From space sharing to sleeping hours and study time, students learn to manage different aspects of life hence become self-reliant. Another important learning is the management of budget as the hostellers get a limited amount to spend. Out of 272, 234 (86\%) participants of our study agreed to the statement of expense management. In addition, the hostel residents have to adjust themselves with persons of different temperament and sometimes undesirable attitudes consequently tolerance, patience, cooperation and art of dealing with other people also remained a characteristic of significance importance learned by living in hostels. Hostels expand one's social circle and in our study a considerable number of students described interaction as an enjoyable experience. As in hostels ,the students mainly belong to same cohort who come from different cultural, social, economical, educational backgrounds thus possess his/her own lifestyle which can influence other students and vice versa. A noteworthy number of girl students (80\%) in the study revealed that they were able to enhance their sense of dressing and get a better look.

For an introvert person it might be hard to interact with other people but while residing and dealing with many people one can develop the capacity and achieve a high level of confidence. In addition, the students can learn strength of mind and fortitude from co hostellers that may assist them to perform better in life thereafter. Besides, hostels not only serve the purpose of accommodation but also aid in study for the dwellers as they better understand curriculum through critical discussions and $84 \%$ of respondents affirmed that hostels serve a conducive environment for study. The limitless freedom, on the other hand may be detrimental for some students. A few can acquire a casual approach towards their studies under the influence of certain careless friends and might get involved into socially and culturally unacceptable activities. Living away from home and the absence of love and care from parents can lead to short spells of distressing feel of loneliness also. It is pertinent to mention that all positive impacts in our study showed a significant positive correlation among them (significant at $\mathrm{p}<.0001$ ).

\section{Conclusion}

The result of our study shows mainly beneficial outcome of hostel life in the pursuit of higher education. Predominantly positive impact perceived by great majority can possibly help dispel any misconceptions which may hinder the achievement of higher education especially for females in a conservative society like Pakistan. Moreover, significant correlation among various study variables may lay a foundation for future research on the topic. A longitudinal study is needed to look for the long term change in the personalities of residents.

\section{References}

1. Hopwood CJ, Donnellan MB, Blonigen DM, Krueger RF, McGue M, et al. (2011) Genetic and environmental influences on personality trait stability and growth during the transition to adulthood: A three-wave longitudinal study. J Pers Soc Psychol 100(3): 545-556.

2. Blonigen DM, Carlson MD, Hicks BM, Krueger RF, Iacono WG (2008) Stability and change in personality traits from late adolescence to early adulthood: A longitudinal twin study. J Pers 76(2): 229-266.

3. Nakao K, Takaishi J, Tatsuta K, Katayama H, Iwase M, et al. (2000) The influences of family environment on personality traits. Psychiatry Clin Neurosci 54(1): 91-95.

4. Iftikhar A, Ajmal A (2015) A qualitative study investigating the impact of hostel life. Int J Emerg Ment Health 17(3): 511-515.

5. Khozaei F, Hassan AS, Khozaei Z (2010) Undergraduate students' satisfaction with hostel and sense of attachment to place: Case Study of University Sains Malaysia. Am J Eng App Sci 3(3): 516-520.

6. Yadav P, Iqbal N (2009) Impact of life skill training on selfesteem, adjustment and empathy among adolescent. J Indian Acad Appl Psychol (35): 61-70.

7. Kalpesh KK, Manoj CS (2019) Problems and challenges faced by hostel students in adjustment. J Advan Schol Res All Edu 16(5): 99-102.

8. Bahadar N, Mahanaz W, Jadoon S, Sobia J (2014) A Comparative analysis of behaviors and performance of day scholars and boarder students at secondary school level. Am J Edu Res 2(8): 600-602.

9. Rizwan F, Shinwari L, Izzat S (2016) Academic performance of day scholars versus boarders in pharmacology examinations of a medical school in Pakistan. J Pak Med Assoc 66(9): 1094-1097. 